\title{
ANTIBACTERIAL AND ANTIBIOFILM ACTIVITY OF QUERCUS INFECTORIA GALLS ON ROTHIA DENTOCARIOSA ISOLATED FROM DENTAL CARIES
}

\author{
AMBULKAR $\mathbf{S}^{1}$, TALE $\mathrm{V}^{1 *}$, KHILARI $\mathrm{S}^{2}$, PAWAR J ${ }^{3}$ \\ ${ }^{1}$ Department of Microbiology, Rajiv Gandhi Institute of IT and Biotechnology, Bharati Vidyapeeth University, Pune, India. ${ }^{2}$ Department \\ of Dravyguna, Bharati Vidyapeeth (Deemed to be University), College of Ayurved, Pune, India. ${ }^{3}$ Department of Nanoscience and \\ Nanotechnology, TERA Research Institute India Pvt Ltd., Pune, India. Email: vstale@gmail.com
}

Received: 28 July 2019, Revised and Accepted: 17 August 2019

ABSTRACT

Objective: The present study aimed to study Quercus infectoria gall extract for phytochemical analysis, antibacterial, and antibiofilm activity against Rothia dentocariosa isolated from dental caries.

Methods: R. dentocariosa was isolated, characterized, and identified by 16S rRNA sequence and also checked for biofilm formation ability. Phytochemical analysis of $Q$. infectoria aqueous gall extracts was carried out. Antibacterial and antibiofilm activity was performed using agar well diffusion method and microtiter plate assay, respectively.

Results: Bacterial isolate from dental caries was identified as R. dentocariosa by 16s rRNA sequencing technique with accession number MH824681 obtained from NCBI. Phytochemical analysis of Q. infectoria aqueous gall extract revealed the presence of alkaloids, phenol, tannin, glycosides, phenolic compound, and flavonoids. Significant antibacterial activity was observed with $19.00( \pm 7.07) \mathrm{mm}$ diameter zone of inhibition. The biofilm inhibition assay was performed by microtiter plate method indicated $92.89 \%$ inhibition of bacteria at the concentration of $100 \mathrm{mg} / \mathrm{mL}$ of aqueous extract.

Conclusion: The results indicated the efficacy of Q. infectoria gall extracts that could be explored as an alternative to current treatment.

Keywords: Rothia dentocariosa, Anti-biofilm activity, Phytochemical screening, Quercus infectoria.

(c) 2019 The Authors. Published by Innovare Academic Sciences Pvt Ltd. This is an open access article under the CC BY license (http://creativecommons. org/licenses/by/4. 0/) DOI: http://dx.doi.org/10.22159/ajpcr.2019.v12i10. 34725

\section{INTRODUCTION}

Dental caries and periodontal diseases are biofilm mediated and have a major public health concern globally. Imbalance of bacteria can cause dental biofilm. A biofilm is a microbial community attached to a solid surface and surrounded by the extracellular polysaccharides and proteins [1]. Formation of biofilm is due to the production of organic acid by bacterial fermentation, resulting in tooth decay or caries.

Rothia dentocariosa is Gram-positive bacteria acts as an opportunistic pathogen present in the oral cavity. R. dentocariosa and other Rothia sp. are involved in the formation of biofilm [2]. It can cause other serious infections such as infective endocarditis, fistula infection, pilonidal abscess, pneumonia, and endophthalmitis [3].

Biofilm protects the bacteria from the surrounding environment, including attacks from antibiotics, antiseptics, and chemotherapeutic agents. These agents have difficulty to reach and affect the pathogenic microorganisms due to the formation of exopolysaccharides [4]. At present, biofilm-mediated antibiotic resistance has a major cause of concern for many clinically associated infections [5]. The increase in resistance and adverse effects has lead researchers to explore novel anti-biofilm compound, which could be used for the effective treatment of oral diseases.

Nature has been a source of biologically important compounds which is used for the treatment of pathogenic infections. In recent days, this natural resource has also received attention worldwide for alternative treatment [6]. Biofilm inhibition is considered a major target for the treatment of dental caries infections. Plant species contain many reported phytochemicals that interfere with biofilm formation which control bacterial infections [7].
The Quercus infectoria (Fagaceae) is a small tree or shrub found in Greece, Asia, and Iran. The gall arise on branches of this tree, resulting from the deposition of eggs by gall wasp [8]. In Indian traditional medicine, the gall have been used to treat diarrhea, dysentery, internal hemorrhages, gonorrhea, impetigo, tonsillitis, and menorrhagia [9]. The present study was to determine phytochemical analysis of $Q$. infectoria aqueous extracts and determine their antibacterial activity and biofilm inhibition activity against $R$. dentocarisa.

\section{METHODS}

Preparation of plant aqueous extracts

The gall of $Q$. infectoria were washed with distilled water, cut into small pieces, and dried at room temperature, before grounding into a fine powder. Aqueous plant extract was prepared from air-dried Q. infectoria gall plant powder. Q. infectoria gall plant powder $(1 \mathrm{~g})$ was added into $25 \mathrm{~mL}$ sterile distilled water and heated on for 10-15 min and filtered through Whatman filter paper.

\section{Isolation and characterization of bacterial isolate}

Isolated bacterial culture from dental caries was identified using $16 \mathrm{~s}$ rRNA technique. Sequences were submitted to Gen bank for accession number. Accession numbers for the isolated $R$. dentocariosa were obtained from NCBI Gen Bank. Biofilm formation ability of isolated bacteria was studied by microtiter plate assay.

Bacterial culture was maintained on brain heart infusion (BHI) agar with $2 \%$ sucrose. Freshly prepared cultures were obtained by inoculation of a loopful of each strain into separated $15 \mathrm{~mL}$ BHI broth and incubated for $24 \mathrm{~h}$ at $37^{\circ} \mathrm{C}$.

\section{Screening for phytochemical compounds}

Screening of Q. infectoria plant extract was carried out for phytochemicals compounds, i.e., alkaloids, phenolic compounds, tannins, proteins, 


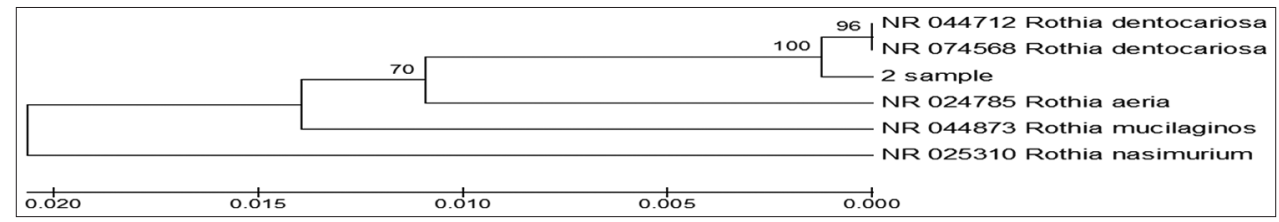

Fig. 1: Phylogenetic tree showing homology to Rothia dentocariosa strain

amino acids, reducing sugar, glycosides, flavonoids, phenols, coumarins, resins, and steroids/terpenoids. These phytochemicals were analyzed as per the standard method $[10,11]$.

\section{Antimicrobial activity}

The antimicrobial activity of $Q$. infectoria plant gall aqueous extracts was performed by modified agar well diffusion assay. Briefly, $100 \mu \mathrm{L}$ of fresh $R$. dentocariosa bacterial culture (approximately $10^{6}$ $\mathrm{CFU} / \mathrm{mL}$ ) was spread uniformly to Mueller-Hinton Agar. Aqueous extracts of $Q$. infectoria galls $(100 \mu \mathrm{L})$ were added to the agar wells. Chlorhexidine was used as a control. Plates were incubated at $37^{\circ} \mathrm{C}$ for $24 \mathrm{~h}$. Antibacterial activity was checked by the presence of a zone of inhibition $[12,13]$

\section{Antibiofilm activity}

The biofilm inhibition effect of gall aqueous extracts on R. dentocariosa was checked using 96 well microtiter polystyrene plate. Different concentration of extract $(10-100 \mu \mathrm{g} / \mathrm{mL})$ was added into each well of a microtiter plate in the presence of different concentrations $(10,25,50$, 75 , and $100 \mu \mathrm{g} / \mathrm{mL}$ ). Briefly, $100 \mu \mathrm{L}$ of bacterial cell suspension (final concentration $10^{6} \mathrm{CFU} / \mathrm{mL}$ ) was added into each well. The plate was then incubated at $37^{\circ} \mathrm{C}$ for $24 \mathrm{~h}$. After incubation, the supernatant was carefully removed without disturbing the adhering cells and washed with sterile distilled water to remove free-floating cells. The plates were air-dried for $15 \mathrm{~min}$ and $100 \mu \mathrm{L}$ ethanol was added to separate the cells adhered to the surface and to remove loosely attached cells. 1\% crystal violet solution was added to observe for the adhered cells. The excess of stain was removed washing with sterile distilled water. Finally, the dye bound to the cells was solubilized by adding $200 \mu \mathrm{L}$ of $95 \%$ glacial acetic acid. Moreover, after $15 \mathrm{~min}$ of incubation, absorbance was measured using microplate reader at a wavelength of $570 \mathrm{~nm}$. Biofilm determination was calculated using this formula $\mathrm{SBF}=(\mathrm{AB}-\mathrm{CW}) / \mathrm{G}$, where SBF is the specific biofilm formation, $A B$ is the $0 D 570 \mathrm{~nm}$ of the attached and stained bacteria, CW is the OD570nm of the stained control wells containing an only bacteria-free medium, and G is cell growth in broth [14].

The data of anti-biofilm assays were analyzed using the SPSS software. The ANOVA test was used to check the differences in mean scores among the groups.

\section{RESULTS}

\section{Characterization of isolated bacteria}

Bacterial isolate from dental caries was identified by 16s rRNA sequencing technique and was found homology to $R$. dentocariosa. Phylogenetic analysis is given in Fig. 1. Sequences were submitted to Genbank NCBI, and accession number (MH824681) was obtained from $\mathrm{NCBI}$. Isolated bacteria were studied for biofilm formation indicated the significant biofilm-forming ability (OD 2.4575 at $570 \mathrm{~nm}$ ) by microtiter plate method.

\section{Phytochemical analysis}

Phytochemical analysis of Q. infectoria gall aqueous extracts indicated the presence of secondary metabolites such as alkaloids, phenolic compound, tannin, glycosides, and flavonoids (Table 1).

\section{Antibacterial activity}

Aqueous extracts of a plant $Q$. infectoria gall were tested for their antibacterial activity against the oral bacteria $R$. dentocariosa.

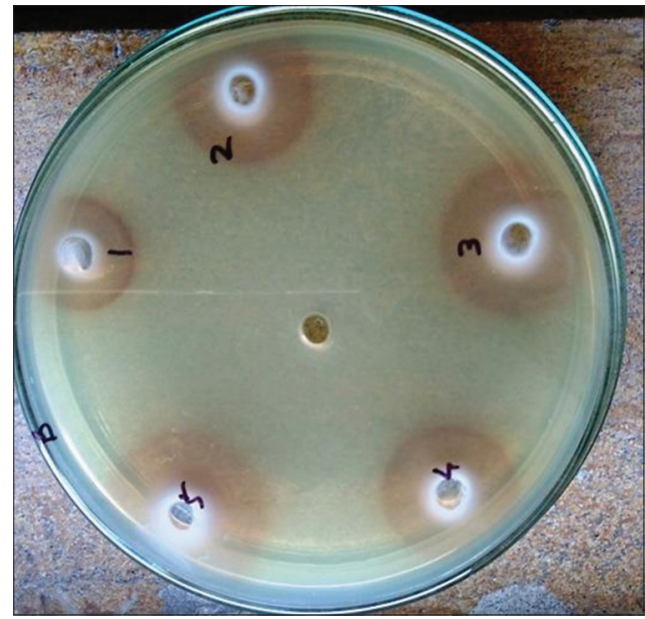

Fig. 2: Antibacterial activity of Quercus infectoria gall extracts against Rothia dentocariosa

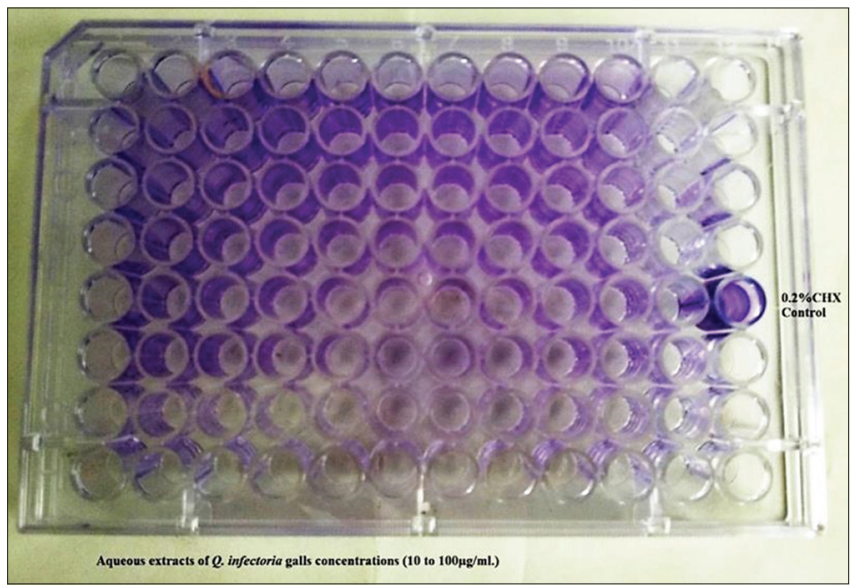

Fig. 3: Antibiofilm assay Quercus infectoria gall extracts against Rothia dentocariosa

Table 1: Phytochemical characterization of plant extract

\begin{tabular}{ll}
\hline Photochemical test & $\begin{array}{l}\text { Quercus infectoria } \\
\text { gall aqueous extracts }\end{array}$ \\
\hline Detection of alkaloids (Hager's test) & + \\
Phenolic compounds (Lead acetate test) & + \\
Tannin (Gelatin test) & + \\
Protein (Nitric acid test) & - \\
Reducing sugar (Benedict's test) & - \\
Glycosides & + \\
Flavonoids & + \\
Phenols (Ferric chloride test) & - \\
Coumarins & - \\
Resins & - \\
\hline
\end{tabular}

+: Indicate the presence of phytochemical compound, -: Indicate the absence of compound 


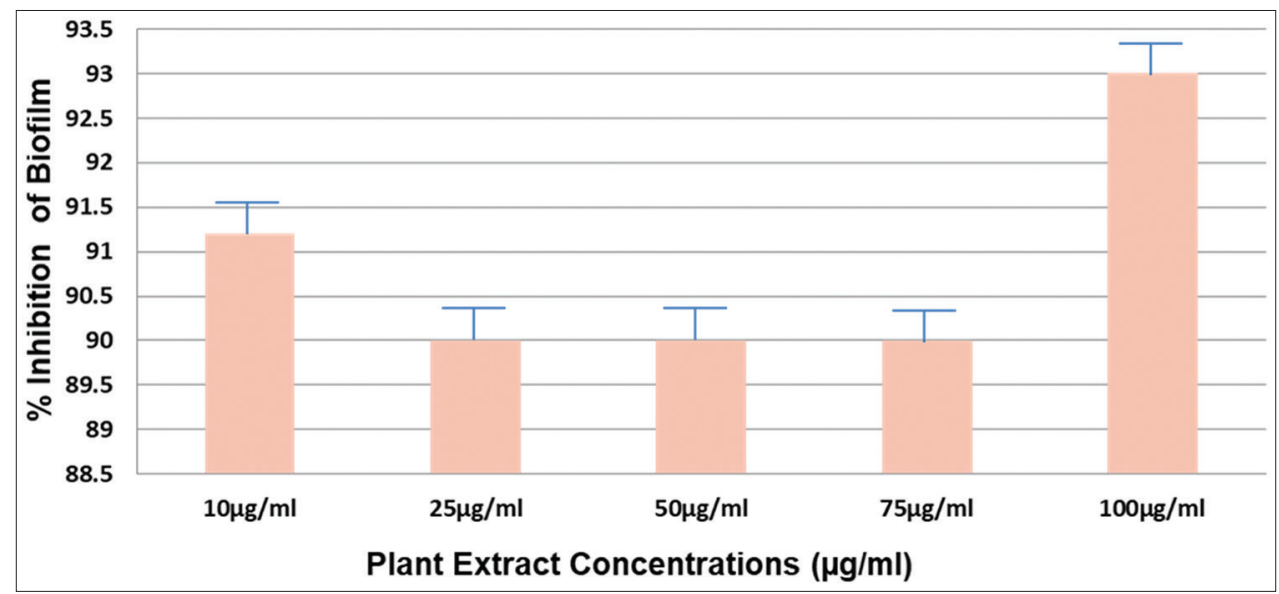

Fig. 4: Quantitative determination of antibiofilm efficacy of Quercus infectoria gall extract against Rothia dentocariosa (a) biofilm reduction assay by microtiter plate. (b) concentration-dependent percentage inhibition of biofilm

Aqueous extracts of $Q$. infectoria gall showed the potent antibacterial activity against $R$. dentocariosa studied by agar well diffusion assay. Chlorhexidine $(0.2 \%)$ having maximum antibacterial efficacy taken as a positive control showing the zone of inhibition $15 \mathrm{~mm}$ against $R$. dentocariosa (Fig. 2). The diameter of zone of inhibition (19.00) $\pm 7.07 \mathrm{~mm}$ was observed at the concentration of $100 \mu \mathrm{g} / \mathrm{mL}$ of extract.

\section{Biofilm inhibition assay}

Biofilm inhibition activity of different concentration aqueous extracts of $Q$. infectoria gall was evaluated by crystal violet staining method. The aqueous extracts of $Q$. infectoria gall showed strong inhibitory effects against $R$. dentocariosa $(\mathrm{p}<0.05)$ (Fig. 3).

Q. infectoria gall has shown anti-biofilm activity at all the concentrations ranging from 10 to $100 \mu \mathrm{g} / \mathrm{mL}$. Chlorhexidine (0.2\%) has taken as a positive control. Maximum anti-biofilm activity (92.89\%) against R. dentocariosa was observed with the extract from $100 \mu \mathrm{g} / \mathrm{mL}$ (Fig. 4).

The values are expressed as percent biofilm inhibition by plant extract, compared with the control (no plant extract) and expressed as means \pm standard deviation of triplicate assays.

\section{DISCUSSION}

$R$. dentocariosa is an opportunistic pathogen of the oral cavity and is responsible for causing dental plaque and dental caries through biofilm formation [15]. In our study, similar results were obtained with significant biofilm formation by the isolated $R$. dentocariosa.

In the present study, screening for photochemical compounds of $Q$. infectoria gall plant aqueous extracts was carried out and observed the presence of secondary metabolites such as alkaloids, phenolic compounds, tannin, glycosides, and flavonoids in the $Q$. infectoria gall plant aqueous extracts. Similar reports were reported by Basri et al. 2012 [8].

The presence of the secondary metabolites in the gall of Q. infectoria could be responsible for antibacterial activity against various pathogens. The high content of tannin in the gall of Q. infectoria is responsible for the antibacterial activity $[16,17]$.

The antibacterial activity of methanol and acetone extracts from galls of $Q$. infectoria against oral bacteria. They observed inhibitory zones showed by methanol and acetone extracts are $22.67 \pm 0.33$ and $21.33 \pm 0.33 \mathrm{~mm}$, respectively, against $S$. mutans [8].

In the present study, we found the significant antibacterial activity $(19.00 \pm 7.07 \mathrm{~mm})$ by galls of $Q$. infectoria in aqueous extracts against $R$. dentocariosa which make it a potentially good source of the antimicrobial compound [18]. Earlier reports indicated percent biomass inhibition from $30.6 \%$ to $87.0 \%$ against $S$. mutans using various concentrations of plant extract [19]. Therefore, Q. infectoria gall extracts and their bioactive compound have shown very good antibacterial, anti-biofilm activity against biofilm-forming $R$. dentocariosa causing dental caries.

\section{CONCLUSION}

Based on this study, Q. infectoria gall aqueous extracts possess a wide range of phytochemicals which demonstrated antimicrobial activities. This study has proved the potential ability of antibacterial $(19.00 \pm 7.07 \mathrm{~mm})$ and antibiofilm $(92 \%)$ of Q. infectoria gall aqueous extract to resist the biofilm growth of $R$. dentocariosa. It could be used as an alternative approach for the prevention of biofilm-forming bacteria. However, further research is needed to study in detail the effect of the gall extracts on different activities involved in dental caries formation and understand the pathogenesis of periodontitis and endodontics.

\section{AUTHOR'S CONTRIBUTIONS}

The author declares that this work was done by the author named in this article.

\section{CONFLICTS OF INTEREST}

The author declares that he has no conflicts of interest.

\section{REFERENCES}

1. Donlan RM, Costerton JW. Biofilms: Survival mechanisms of clinically relevant microorganisms. Clin Microbiol Rev 2002;15:167-93.

2. Khan ST, Ahamed M, Musarrat J, Al-Khedhairy AA. Anti-biofilm and antibacterial activities of zinc oxide nanoparticles against the oral opportunistic pathogens Rothia dentocariosa and Rothia mucilaginosa. Eur J Oral Sci 2014;122:397-403.

3. Morris SK, Nag S, Suh KN, A Evans G. Recurrent chronic ambulatory peritoneal dialysis-associated infection due to Rothia dentocariosa. Can J Infect Dis Med Microbiol 2004;15:171-3.

4. Rutherford ST, Bassler BL. Bacterial quorum sensing: Its role in virulence and possibilities for its control. Cold Spring Harb Perspect Med 2012;2:a012427.

5. Chen L, Wen YM. The role of bacterial biofilm in persistent infections and control strategies. Int J Oral Sci 2011;3:66-73.

6. Sánchez E, Morales CR, Castillo S, Leos-Rivas C, García-Becerra L, Martínez DM. Antibacterial and antibiofilm activity of methanolic plant extracts against nosocomial microorganisms. Evid Based Complement Alternat Med 2016;2016:8

7. Ta CA, Arnason JT. Mini review of phytochemicals and plant taxa with activity as microbial biofilm and quorum sensing inhibitors. Molecules 
2015;21:E29.

8. Basri DF, Tan LS, Shafiei Z, Zin NM. In vitro antibacterial activity of galls of Quercus infectoria Olivier against oral pathogens. Evid Based Complement Alternat Med 2012;2012:632796.

9. Grant SS, Hung DT. Persistent bacterial infections, antibiotic tolerance, and the oxidative stress response. Virulence 2013;4:273-83.

10. Maroyi A. Medicinal uses, biological and phytochemical properties of Helichrysum foetidum (L) moench.(Asteraceae). Asian J Pharm Clin Res 2019;12:13-8.

11. Firdouse S, Alam P. Phytochemical investigation of extract of Amorphophallus campanulatus tubers. Int J Phytomed 2011;3:32-5.

12. Shirsat S, Pawar D, Jain N, Pawar J, Tale V, Henry R. Synthesis of copper oxide nanoparticles by chemical precipitation method for determination of antibacterial efficacy against Streptococcus sp. and Staphylococcus sp. Asian J Pharm Clin Res 2019;12:35-138.

13. Njimoh DL, Assob JC, Mokake SE, Nyhalah DJ, Yinda CK, Sandjon B. Antimicrobial activities of a plethora of medicinal plant extracts and hydrolates against human pathogens and their potential to reverse antibiotic resistance. Int J Microbiol 2015;2015:15.

14. Murugan K, Selvanayaki K, Al-Sohaibani S. Antibiofilm activity of Andrographis paniculata against cystic fibrosis clinical isolates Pseudomonas aeruginosa. World J Microbiol Biotechnol 2011;27:1661 8

15. Karpiński1 TM, Szkaradkiewicz AK. Microbiology of dental caries. J Biol Earth Sci 2013;3:21-4.

16. Issac Abraham SV, Palani A, Ramaswamy BR, Shunmugiah KP, Arumugam VR. Antiquorum sensing and antibiofilm potential of Capparis spinosa. Arch Med Res 2011;42:658-68.

17. Scalbert A. Antimicrobial properties of tannins. Phytochemistry 1991;30:3875-83

18. de Miranda CM, van Wyk CW, van der Biji P, Basson NJ. The effect of areca nut on salivary and selected oral microorganisms. Int Dent J 1996;46:350-6.

19. Mohammadi-Sichani M, Karbasizadeh V, Dokhaharani SC. Evaluation of biofilm removal activity of Ouercus infectoria galls against Streptococcus mutans. Dent Res J (Isfahan) 2016;13:46-51. 